\title{
1 Butanol production via vacuum fermentation: an economic evaluation of operating
}

\section{2 strategies}

3 Víctor Hugo Grisales Díaz , Moritz von Stosch and Mark J Willis

4 School of Engineering, Newcastle University, NE1 TRU, Newcastle upon Tyne, United Kingdom

5 5victor.grisales-diaz@newcastle.ac.uk,vhgrisalesd@unal.edu.co

\section{Abstract}

7 Butanol production from corn stover via (acetone-butanol-ethanol) ABE fermentation under

8 vacuum was studied in this work. The reactor operating strategies considered were batch, fed-

9 batch and continuous. The integrated reactor and vacuum separation process includes energy integration by a heat-pump system as well. A mathematical model describing the dynamics of the integrated reactors and the network of compressors and heat exchangers has been developed. The dynamic process models were used to select the optimum production strategy using economic optimisation where a methodology to determine the effect of scheduling of parallel reactor operation on the sizing of the heat-pump system was developed. The results suggest that the optimal operating mode for the integrated reaction system was fed-batch. Although the fed-batch process had the highest economic potential (37.8 MM USD), the compressor work for batch process operation (36.6 MM USD) was the lowest (1.8 MJ/kg ABE, $18 \%$ lower than that of fed-batch). Continuous process operation demonstrated the lowest economic potential (23.8 MM USD) and the highest compression work (2.87 MJ/kg ABE). The energy requirements of the purification system, a double-effect distillation process, were found to be between 3.45 and $4.14 \mathrm{MJ} / \mathrm{kg} \mathrm{ABE}$.

Keywords: Butanol production; heat pump; dynamic modelling; scheduling; economic optimisation; batch, fed-batch, continuous operation 


\section{Nomenclature}

28 CAPEX, capital expenditures (USD/year)

29 CCR, carbon catabolite repression (-)

$30 C p_{k}$, mean calorific heat capacity between the stage $\mathrm{k}$ and $\mathrm{k}+1(\mathrm{MJ} / \mathrm{kg} / \mathrm{K})$

$31 E P$, economic potential (USD/year)

$32 \quad F_{0}$, flow of feed $(\mathrm{mmol} / \mathrm{h})$

$33 F_{P}$, flow of bleed or purge stream $(\mathrm{mmol} / \mathrm{h})$

$34 F_{G}$, flow of gas stream $(\mathrm{mmol} / \mathrm{h})$

$35 K_{P}$, proportional gain for pressure control $(\mathrm{mmol} / \mathrm{bar} / \mathrm{h})$

$36 K_{V}$, proportional gain for volume control $(\mathrm{mmol} / \mathrm{l} / \mathrm{h})$

$37 H$, parameter of Henry's solubility (bar)

$38 H X$, heat exchanger

$39 I_{C}$, investment cost of compressors (USD)

$40 I_{H X}$, installation cost of heat exchangers (USD)

$41 I_{R}$, installation cost of a reactor (USD)

42 ISPR, in situ recovery reactor

$43 \quad L M T D$, logarithmic mean temperature difference $(\mathrm{K})$

$44 \quad M W$, molecular weight $(\mathrm{g} / \mathrm{mol})$

$45 \quad N$, amount of a component in the reactor $(\mathrm{mmol})$

$46 \quad N_{R}$, number of reactors

$47 \quad N_{V}$, number of reactors operated under vacuum with respect to time

48 OPEX, Operating expense (USD/year)

$49 \quad p$, parameter describing death of biomass

$50 \quad P$, pressure (bar)

$51 \quad P_{\text {set }}$, pressure set-point (bar)

$52 \quad P_{V}$, vapour pressure (bar) 
$53 Q_{C V}$, heat of condensation of the heat exchangers

$54 r_{i}$, rate of production / consumption of component $i$ in the fermentation $(\mathrm{mmol} / \mathrm{h})$

$55 \quad r_{s}$, parameter relating glucose and substrate consumption

$56 r_{w i}$, sacharification reaction rate of component, $i(\mathrm{~g} / \mathrm{h} / \mathrm{kg})$

$57 R$, global reaction rate of component $i$ in the fermentation $(\mathrm{mmol} / \mathrm{h} / \mathrm{l})$

$58 R_{C}$, reactivity parameter for cellulose conversion (g/g)

$59 R_{\text {cte }}$, universal gas constant $(\mathrm{J} / \mathrm{mol} / \mathrm{K})$

$60 R_{W}$, global reaction rate for hydrolysis $(\mathrm{g} / \mathrm{kg} / \mathrm{h})$

$61 S_{M}$, ratio between the average and the maximum compressor work on the cycle time (-)

$62 t$, time (h)

$63 t_{d}$, time between the start-up of the reactors (h)

$64 t_{f}$, total fermentation time $(\mathrm{h})$

$65 t_{t}$, cycle time $(\mathrm{h})$

$66 T$, temperature $(\mathrm{K})$

$67 \quad T_{C R}$, critical temperature (K)

$68 V_{F}$, total volume of liquid components in the reactor (I)

$69 \quad V_{\text {set }}$, volume set-point (I)

$70 V_{T}$, total volume of broth in the reactor (I)

$71 x$, liquid composition in the reactor $(\mathrm{mol} / \mathrm{mol})$

$72 w$, mass fraction

$73 W$, compressor work (MJ/h)

$74 \quad y$, gas composition $(\mathrm{mol} / \mathrm{mol})$

$75 \quad z$, compressibility factor

76 Greek symbols

$77 \omega$, weighting factor for consumption of glucose and xylose

$78 \rho$, density $(\mathrm{g} / \mathrm{l})$ 
$\alpha$, coefficient of activity (liquid phase)

$80 \gamma$, coefficient of activity (vapour phase)

$81 \eta$, isentropic efficiency

$82 \kappa_{r}$, specific heat ratio $\left(C p /\left(C p-R_{c t e}\right)\right)$

83 Subscripts

$84 i$, component in the biochemical network

$85 j$, component of the gas stream

$86 k$, compression stage

$87 S$, substrate

$88 L$, liquid from heat exchangers

89 Superscript

$90 M$, maximum

$91 \quad S$, scheduling

$92 \quad A$, average

93

94

95

96

97

98

99

100

101

102

103 
ABE (acetone-butanol-ethanol) are alternative biofuels. Unfortunately, their production by fermentation is currently limited by butanol inhibition and low substrate yield (Raganati et al., 2016; Zheng et al., 2015). Furthermore, while lignocellulose (LCB) substrates of low cost, such as corn stover, represent attractive options when compared to conventional substrates, LCB consumption by the microorganism is known to be difficult, because of the high degree of biomass polymerisation (Ghosh et al., 2017). Therefore, in order to maximise ABE yield and reactor productivity from corn stover, pre-treatment and enzymatic hydrolysis are required. Unfortunately, the inhibition of soluble sugars during enzymatic hydrolysis (Kadam et al., 2004) reduces the conversion rate of cellulose to glucose and, in addition, carbon catabolite repression (CCR) minimises the utilization of secondary carbon sources (e.g. xylose) during fermentation (Ren et al., 2010; Servinsky et al., 2010). to intensify the process (Grisales Díaz and Olivar Tost, 2016a). As butanol inhibition is reduced by the separation units, in situ product recovery (ISPR) increase ABE productivity and yield when compared to conventional processing methods (Qureshi et al., 2014). The in situ recovery methods studied the most for bio-butanol production are gas stripping, vacuum evaporation, liquid-liquid extraction, adsorption, and pervaporation (Kujawska et al., 2015). It is important to mention that although these processes improve reactor performance (i.e., the butanol productivity may be increased more than two times (Sharif Rohani et al., 2015)), heatintegrated distillation schemes have been recently reported with lower energy requirements than that of integrated recovery and reaction methods (Grisales Diaz and Olivar Tost, 2018; Xue et al., 2013). Pervaporation or adsorption have been shown to have a low energy requirement due to the high selectivity of some of the membranes (e.g. the butanol separation factor of poly[1(trimethylsilyl)-1-propyne] is 104 (Claes et al., 2012)) or adsorbents (e.g. butanol is 
concentrated from 0.5 to $98 \%$ by adsorption on silicalite (Milestone and Bibby, 1981)).

However, the high fouling in these processes hinder their industrial use for butanol production

132 from lignocellulose (Dubreuil et al., 2013; Xue et al., 2016). Similarly, liquid-liquid extraction have low energy requirements (8.4 MJ/kg butanol (Qureshi et al., 2005)). However, emulsion formation and control must be further studied in this multi-phase (liquid-liquid, solid and gas) process. Although it has been reported that gas stripping has a high energy requirement (23.1 the fermentation $\left(\mathrm{CO}_{2}\right.$ and $\left.\mathrm{H}_{2}\right)$ may be use to recover the volatile components and due to the low risk of fouling (Oudshoorn et al., 2009).

Butanol selectivities in gas stripping are similar to the relative volatility of butanol under vacuum (<30, (Grisales Díaz and Olivar Tost, 2016a; Xue et al., 2014)). However, vacuum evaporation has been reported with low energy requirements $13.4 \mathrm{MJ} / \mathrm{kg}$ (Mariano et al., 2011) as the evaporation heat may be recovered using heat pump systems. Application of a heat-pump system in gas stripping is more difficult due to the elevated flow gas required. Although vacuum stripping is possibly one of the best economic and technical options, it is in an early stage of its development (Tao et al., 2014). For these reasons, bio-butanol production by vacuum evaporation is considered in this work. The determination of the best mode of operation (batch, fed-batch or continuous) can be challenging because each mode has advantages in terms of either yield, productivity, enzyme load or energy requirements (Tao et al., 2014); and there is a significant number of operating variables that can be adjusted in order to optimise performance. In our previous work, the energy requirements and total annualised costs of continuous vacuum

152 fermentations were determined. However, this was based upon steady-state assumptions 153 (continuous fermenters operating for of $500 \mathrm{~h}$ ), i.e. the implications and requirements of batch and fed-batch operation were not studied. In addition, a kinetic model that did not consider 
carbon catabolite repression and gave inaccurate butanol predictions at high concentrations was used (Grisales Díaz and Willis, 2018).

The aim of this work is to select the operating strategy for ABE production from corn stover using vacuum fermentation by maximisation of the economic potential $(E P)$. The $E P$ was considered in order to address the conflicting criteria of productivity, yield, enzyme load, and process energy requirements. As batch and fed-batch operation are considered, scheduling of the operation of the ancillary units within the process flowsheet is also required in order to determine the operating regime that maximises the $E P$.

\subsection{The process}

In this work, the focus is ISPR by vacuum evaporation (ISPR-V). A set of parallel reactors are operated such that saccharification, fermentation, and recovery are achieved simultaneously.

The proposed flowsheet is shown in Fig. 1. In addition to the reactor(s) a network of compressors and heat exchangers are required as the reactors operate under vacuum conditions.

A number of different configurations of this compression arrangement have been considered in the literature (Abdi et al., 2016; Mariano et al., 2011; Pereira et al., 2017) and because of the high energy requirements of the process, the energy efficiency of the vacuum fermentation needs be improved using heat pump systems. In the process flowsheet, Fig. 1, the energy obtained through condensation of the gas stream is used to provide the energy for evaporation within the reactor(s). In previous work, the use of a heat pump has been proposed where excess condensation energy is used to supply energy to the boiler of the acetone purification column. Total energy requirements of 13.4 and $22.3 \mathrm{MJ} / \mathrm{kg}$ butanol for continuous operation (Mariano et al., 2011) and between 22 and $32.4 \mathrm{MJ} / \mathrm{kg}$ butanol for batch (Mariano et al., 2012a) have been reported, demonstrating that both the final purification system and the configuration of the compression system are affected by the operational mode. Our previous work reported the use of an integrated heat pump to provide the energy of evaporation within 
the reactor, the excess energy was not used in the purification system, which used a highly efficient distillation process instead (Grisales Díaz and Olivar Tost, 2016a), i.e. a double-effect distillation (DED) process. This reduced the total energy requirements for continuous operation to $5.9 \mathrm{MJ} / \mathrm{kg} \mathrm{ABE}$ or $9.1 \mathrm{MJ} / \mathrm{kg}$ butanol (or $10.8 \mathrm{MJ}$ fuel/kg ABE, calculated assuming an efficiency of production from fuel of electricity and steam of 0.33 and 0.9 , respectively). For batch and fed-batch operation, the power and the cooling water required by the heat pump system will change with respect to time because each fermentation starts at atmospheric pressure and then there is a change to vacuum (0.045-0.07 bar) operation. Altering the mode of operation, between atmospheric and vacuum has the potential to reduce the process energy requirements as the time-period and operating pressure of the system can be adjusted. Moreover, as it is assumed that there are multiple reactors operating in parallel, the optimal scheduling of these reactors will determine their optimal start-up times and periods of vacuum operation in order to minimise the investment costs of compressors as well as operating costs. Assuming batch and fed-batch operation therefore implies that the initial investment (and sizing) of the heat pump system will depend on the maximum work and condensation heat required at any given time as a result of the optimally scheduled operation. This is a complex problem as a high number of reactors will be required, because $A B E$ fermentation has a low productivity (between 0.11 and $0.68 \mathrm{~g} / \mathrm{l} / \mathrm{h}$ (Yao et al., 2017)). For this reason, to find the maximum required compressor work, a short-cut scheduling method is proposed. To the best of our knowledge, the scheduling of dynamic ISPR by vacuum evaporation (ISPR-V) for butanol production has not been studied in the literature.

\subsection{Process modelling}

In order to study and optimise the performance of the reaction system a dynamic process model is required. The model needs a) an accurate biochemical reaction network; $\mathbf{b}$ ) a kinetic description of all the reactions occurring within the system; c) dynamic equations (material balance expressions) describing the rate of change of the species in the reactor; and d) models 

the flowsheet (Fig. 1).

\subsection{The biochemical reaction network}

210

The proposed biochemical reaction network for simultaneous saccharification and ABE fermentation is shown in Fig. 2. The rate of production / consumption of each component in $\mathrm{ABE}$ fermentation and saccharification is represented by $R_{i}(\mathrm{mmol} / \mathrm{l} / \mathrm{h})$ and $R_{W i}(\mathrm{~g} / \mathrm{kg} / \mathrm{h})$, respectively. For saccharification the mass rate of production / consumption of each of the species are given by,

$$
\begin{aligned}
& R_{W \text { Cellubiose }}=1.056 \cdot r_{w 1}-r_{w 3} \\
& R_{W \text { Cellulose }}=-r_{w 1}-r_{w 2} \\
& R_{W \text { Glucose }}=1.111 \cdot r_{w 2}+1.053 \cdot r_{w 3}
\end{aligned}
$$

where the constants are calculated based in the stoichiometric reactions assumed by Kadam et al., (2004).

217 The global rates of reaction of $\mathrm{CO}_{2}$ and $\mathrm{H}_{2}$ were calculated assuming stoichiometric conversions of glucose and xylose in relation to the main products: acetone, ethanol and butanol. Hydrogen is only produced in the stoichiometric reaction with acetone (see Fig. 2), where the stoichiometric coefficient of $\mathrm{H}_{2}$ was four times that of the acetone, i.e. the global rate of $\mathrm{H}_{2}$ was four times that of acetone. While, three, two and one moles of $\mathrm{CO}_{2}$ are made for each mole of acetone, butanol and ethanol produced (Fig. 2), respectively. It was assumed that six moles of xylose has the same yield as five moles of glucose (Humbird et al., 2011) (see Fig. 2).

224 Hence, the rate of production of $\mathrm{H}_{2}$ and $\mathrm{CO}_{2}$ depends on the rates of consumption of glucose and xylose,

$$
\begin{aligned}
& R_{\mathrm{H}_{2}}=4 \cdot\left(r_{4}+r_{11}\right) \cdot\left(r_{s}+5 / 6 \cdot\left(1-r_{s}\right)\right) \\
& R_{\mathrm{CO}_{2}}=\left(3 \cdot\left(r_{4}+r_{11}\right)+2 \cdot r_{14}+r_{7}\right) \cdot\left(r_{s}+5 / 6 \cdot\left(1-r_{s}\right)\right) \\
& r_{S}=R_{\text {Glucose }} /\left(R_{\text {Glucose }}+R_{\text {Xylose }}\right)
\end{aligned}
$$


226 In similar way, the mass rate of production / consumption of water is calculated in relation to

227 the stoichiometric reactions assumed in Fig. 2,

$$
R_{W \text { Water }}=\left(-r_{4}-r_{11}+r_{14}\right) \cdot\left(r_{s}+5 / 6 \cdot\left(1-r_{s}\right)\right) \cdot 0.018-0.056 \cdot r_{w 1}-0.111 \cdot r_{w 2}-0.053 \cdot r_{w 3}
$$

In addition, CCR was estimated assuming competitive carbohydrates uptake (Grisales Díaz and given by,

$$
\begin{aligned}
& R_{\text {Biomass }}=r_{16} \cdot(1-\omega)+r_{8} \cdot \omega-R_{\text {Biomass death }} \\
& R_{\text {Biomass death }}=\left(r_{17} \cdot(1-\omega)+r_{9} \cdot \omega\right) \cdot p \\
& R_{\text {Glucose }}=-r_{1} \cdot \omega \\
& R_{\text {Xylose }}=-r_{15} \cdot(1-\omega) \\
& R_{\text {Pyruvate }}=-r_{2}+r_{1} \cdot \omega+r_{15} \cdot(1-\omega) \\
& R_{\text {AcoA }}=r_{2}+r_{3}+r_{4}-r_{5}-r_{6}-r_{7} \\
& R_{\text {AACoA }}=r_{6}-r_{10}-r_{4}-r_{11} \\
& R_{\text {Acetate }}=r_{5}-r_{4}-r_{3} \\
& R_{\text {Ethanol }}=r_{7} \\
& R_{\text {Acetone }}=r_{4}+r_{11} \\
& R_{\text {Butyrate }}=r_{13}-r_{12}-r_{11} \\
& R_{\text {BCoA }}=r_{10}+r_{11}+r_{12}-r_{13}-r_{14}-r_{16} \cdot(1-\omega)-r_{8} \cdot \omega \\
& R_{\text {Butanol }}=r_{14}
\end{aligned}
$$
The death rate of biomass is zero for continuous operation, i.e. $p$ is zero for continuous operation and one for fed-batch or batch. The kinetic model for ABE fermentation by Clostridium saccharoperbutylacetonicum N1-4 was developed in our previous work (Grisales Díaz and Willis, 2018) (Table A1). The parameters of these models are reported in the Table

235 A2. The kinetic model gives good predictive performance in batch fermentations using both 236 xylose and glucose as individual substrates, at high concentrations of substrate and biomass, in 237 mixture of substrates, and in continuous operation with and without biomass recycling and 
bleeding. The kinetic model describing saccharification was proposed by Kadam et al., (2004)

239 (Table A1) and it has been widely used in a number of design and process optimisation studies

240 (Morales-Rodriguez et al., 2011; Quiroz-Ramírez et al., 2018). The parameters of this model are reported in Table A3.

\subsection{Modelling the reactor}

243 In order to mathematically model the reactor, isothermal operation is assumed $\left(30^{\circ} \mathrm{C}\right)$. To describe dynamic operation of each reactor, including start-up for continuous operation, the material balances for each of the components are required. These are given by a set of ordinary differential equations (ODEs) describing the rate of change of the moles of each component $\left(N_{(i)}\right)$ with respect to time $(t)$,

$$
\frac{d N_{(i)}}{d t}=R_{(i)} \cdot V_{F}+R_{w(i)} \cdot V_{T} \cdot \rho / M W_{(i)}+F_{A} \cdot x_{A(i)}-F_{P} \cdot x_{0(i)}-F_{G(0)} \cdot y_{0(i)}
$$

Eq. (21) assumes no mass transfer resistances between the solid-liquid and liquid-gas phase.

These assumptions are valid when the concentrations of non-soluble solids in the hydrolysis are lower than $20 \%$ (Hodge et al., 2008). Therefore, to minimise the effect of the mass transfer resistances in the fermentation and hydrolysis, the concentration of non-soluble solids in the reactor were specified as being lower than $100 \mathrm{~g} / \mathrm{l}$. In Eq. (21), $F_{G(0)}$ is the molar flow of gas $(\mathrm{mmol} / \mathrm{h})$. For batch operation of ISPR-V, there is no feed, i.e. the dilution rate $F_{A}=0$, while, for continuous and fed-batch operation there is a feed-stream. The difference between continuous operation and fed-batch are defined in relation to the bleed stream. If the reactor has no bleed, $F_{P}=0$, the reactor is fed-batch, while, continuous operation implies the presence of a bleed stream. In addition, $x_{0}$ are the mole fractions of each component in the reactor $(N i / \Sigma N i)$ and $x_{A}$ and $y_{0}$ are the molar compositions in the feed and the gas phase, respectively. $\rho$ is the average density of the media $(\mathrm{g} / \mathrm{l})$ and $M W_{(i)}(\mathrm{g} / \mathrm{mol})$ is the molecular weight of each component. The total volume of the fermentation broth, $V_{T}$ (I) (including solids 

assuming additive volumes, i.e. an ideal mixture.

263 The set of differential equations is completed by,

$$
\begin{aligned}
& \frac{d N_{(C)}^{X}}{d t}=x_{0(C)} \cdot F_{P} \\
& \frac{d N_{(C)}^{F}}{d t}=x_{A(C)} \cdot F_{A} \\
& R_{C(t)}=\frac{d N_{(C)}^{X}}{d N_{(C)}^{F}}
\end{aligned}
$$

264 where, $x_{A(C)}$ and $x_{0(C)}$ are the molar compositions of cellulose $(C)$ in the feed stream and

265 reactor or bleeding, respectively, and $N_{(C)}^{F}$ and $N_{(C)}^{X}$ are the total amounts of cellulose fed and 266 unconverted, respectively. Eq. (22) and (23) allow the calculation of, $R_{C}$, the cellulose reactivity 267 (Eq. (24)). These differential equations are required because the substrate concentrations in the feed stream and the initial substrate concentration of the reactor may be different. In order to determine the gas flow $\left(F_{G(t)}\right)$ and the flow of the bleeding stream $\left(F_{P(t)}\right)$ it is assumed that they are manipulated using a proportional control law (Grisales Díaz and

271 Olivar Tost, 2016a),

$$
\begin{aligned}
& F_{G(t)}=K_{P} \cdot\left(P_{(t)}-P_{s e t}\right) \\
& F_{P(t)}=K_{V} \cdot\left(V_{T(t)}-V_{s e t}\right)
\end{aligned}
$$

$272 V_{\text {set }}$ and $P_{\text {set }}$ are the volume (I) and pressure (bar) set-points and $K_{V}(\mathrm{mmol} / \mathrm{l} / \mathrm{h})$ and $K_{P}$

$273(\mathrm{mmol} / \mathrm{bar} / \mathrm{h})$ are the controller gains. The numerical value of the controller gains was chosen via trial and error to ensure a stable (closed loop) response.

275 The compositions of volatile components in the gas stream $\left(y_{i}\right)$ within the reactor are calculated using the modified Raoult's law,

$$
y_{(k, i)} \cdot P_{(k)}=x_{(k, i)} \cdot \alpha_{(k, i)} \cdot P_{V(k, i)} / \gamma_{(k, i)}
$$

277 The coefficients of activity of the volatile components in the liquid phase $(\alpha)$ and the gas

278 stream $(\gamma)$ were calculated using UNIQUAC and Peng-Robinson's equation state, respectively. 

algorithm (Henley et al., 2011). Henry's law was used to estimate the concentration in the liquid phase of non-condensable gases. Hence, $\mathrm{H}_{2}$ and $\mathrm{CO}_{2}$ compositions were estimated as,

$$
y_{(k, i)} \cdot P_{(k)}=x_{(k, i)} \cdot H_{(k, i)}
$$

Henry's law constants for the estimation of solubility $\left(H_{(k, i)}\right)$ in water of $\mathrm{H}_{2}$ and $\mathrm{CO}_{2}$ are reported by Sander, (2015).

\subsection{Modelling of the heat exchanger and compressor units}

Although the vacuum pressure and gas flow and composition changes slightly with respect to

time, it was assumed that the vacuum pressure and the species flow rates into the heat-pump system were at their respective average values. This assumption allows the simulation of only one reactor in the scheduled process.

The number of compression stages used in this work was three (Fig. 1). The global material balance around the heat exchanger of stage $k(k=1, \ldots, 3)(H X$, in Fig. 1$)$ were modelled in the same way as a conventional flash. Therefore,

$$
\begin{aligned}
& F_{G(k)}=F_{L(k)}+F_{G(k+1)} \\
& F_{G(k)} \cdot y_{G(k, i)}=F_{L(k)} \cdot x_{L(k, i)}+F_{G(k+1)} \cdot y_{G(k+1, i)}
\end{aligned}
$$

In Eq. (29) and Eq. (30), $F_{G(k)}$ and $F_{L(k)}$ are the average flows of liquid and gas, respectively

293 (note that all the reactors are defined as stage ' 0 ', i.e. $k=0$ ). The gas $\left(y_{G(k, i)}\right)$ and liquid

$294\left(x_{L(k, i)}\right)$ compositions of components $(i)$ in the outputs of $H X_{(k)}$ were found by simultaneously solving the equilibrium equations (Eq. (27) - Eq. (28)) and mass balance equations (Eq. (29) Eq. (30)) through the flash algorithm proposed by Henley et al., (2011). For ISPR-V it is assumed that there are two operating zones which are used to reduce the operational costs, one atmospheric period (no energy requirements) and a vacuum period. Vacuum fermentations for butanol production have been studied experimentally in several works (Mariano et al., 2012b; Qureshi et al., 2014) and the strategy adopted in this work is 
at atmospheric conditions and then if the butanol concentration is high enough $\left(>5 \mathrm{~g} \mathrm{I}^{-1}\right)$ vacuum operation starts. The change between atmospheric and vacuum operation is determined through optimisation of the pressure controller set-point. Eq. (27) - Eq. (30) are used for both zones of operation. The maximum pressure controller set-point is $1.1 \mathrm{~atm}$. If the set-point is lower than the maximum (1.1 atm), vacuum operation is assumed and equations (Eq. (31) - Eq. (34)) are used to calculate the average compressor work and heat of condensation. In the heat-pump system, only the first stage is used to supply energy due to evaporation in the fermenter and the minimum approach temperature of its boiler-condenser was assumed to be $10^{\circ} \mathrm{C}$ (or $T_{C}$ was $40{ }^{\circ} \mathrm{C}$ ). The $T_{C}$ of condensers that use cold water $(\mathrm{CW}, 18$ $25^{\circ} \mathrm{C}$ ) was specified as being $30^{\circ} \mathrm{C}$. This allows the maximum energy requirements of cooling, $Q_{c(k)}$, of each of the heat exchangers to be calculated as,

$$
\begin{aligned}
& Q_{c(k)}=-\sum F_{L(k)} \cdot \Delta H_{c(k, i)} \cdot x_{L(k, i)}-F_{G(k)} \cdot \int_{T c(k)}^{T(k)} \sum_{i} C p_{i} \cdot x_{G(k, i)} \cdot d T \\
& \Delta H_{c(k, i)}=A_{i} \cdot\left(1-T_{C(k)} / T_{C R(i)}\right)^{n_{(i)}}
\end{aligned}
$$

The parameters $\left(A_{i}\right.$ and $\left.n_{i}\right)$ of the volatile components are reported by Yaws and Satyro, (2009); if the component (i) are gases $\left(\mathrm{H}_{2}\right.$ or $\left.\mathrm{CO}_{2}\right)$, Ai was assumed to be zero. $T_{C R(i)}$ is the critical temperature of components $(i) . C_{p i}$ is the gaseous calorific heat capacity of the component $i$.

For compressor $\left(W_{(k)}(\mathrm{MJ} / \mathrm{h})\right)$, the compression work was calculated using the mean properties of the gas between stage $k-1$ and $\mathrm{k}$ using (Fontalvo et al., 2005):

$$
\mathrm{W}_{(k)} \cdot \eta_{s}=\frac{\kappa_{r}}{\kappa_{r-1}} \cdot z \cdot R_{c t e} \cdot T_{(k-1)} \cdot\left[\left(\frac{P_{(k)}}{P_{(k-1)}}\right)^{\frac{\kappa_{r-1}}{\kappa_{r}}}-1\right]
$$

where, $z$ is the compressibility factor, $R_{c t e}$ is the constant of ideal gases $(\sim 0.083 \mathrm{MJ} / \mathrm{kmol} / \mathrm{K})$, $\kappa_{r}$ is the specific heat ratio $\left(C p /\left(C p-R_{c t e}\right)\right)$ and the isentropic efficiency $\left(\eta_{s}\right)$ of the compressor was assumed to be 0.75 (Vane et al., 2013). However, to take into consideration the different isentropic efficiencies of vacuum pumps reported in the literature (between 0.5 
and 0.75 (Sreemahadevan et al., 2018)), once the best operating mode is selected, optimisation using different $\eta_{s}$ were performed. In addition, it has been reported that $\eta_{s}$ for vacuum systems may be calculated as a function of the input and output pressures (Belaissaoui et al., 2016; Matsumiya et al., 2005). This is also studied in the section 4.3 using different numbers of compression stages. To the best of our knowledge the effect that these two variables have on both economic and energy performance has been not studied in the literature. inlet. The temperature $(T)$ at the exit of the compressor is calculated via,

$$
T_{(k)}=T_{(k-1)}+\frac{T_{(k-1)}}{\eta_{s}}\left[\left(\frac{P_{(k)}}{P_{(k-1)}}\right)^{\frac{\kappa_{r}-1}{\kappa_{r}}}-1\right]
$$

\subsection{Scheduling of the reactors}

The annual operating time $\left(t_{a}\right)$ is given by,

$$
t_{a}=8760 \cdot\left(1-4 / t_{t}-1 / 20\right)
$$

334 In this equation, $t_{t}$ is defined as the sum of fermentation time $\left(t_{f}\right)$ and the cleaning / turnaround time (which is assumed to be $4 \mathrm{~h}$ ). An additional time for the maintenance of each reactor (independent of $t_{t}$ and reactor operation mode) of 1 day every 20 days has been assumed. This allows the annual electricity consumption of the compressors and the annual cold water requirement for the heat-exchangers to be obtained by multiplying $t_{a}$ by $\mathrm{W}_{(k)}{ }^{A}$ or

$339 \mathrm{Q}_{c(k)}{ }^{A} \cdot \mathrm{W}_{(k)}{ }^{A}$ and $\mathrm{Q}_{c(k)}{ }^{A}$ are the average compressor work and heat of condensation taking account of both periods of operation, i.e. atmospheric and vacuum respectively,

$$
\begin{aligned}
& \mathrm{W}_{(k)}{ }^{A}=\frac{t_{v}}{t_{t}} \cdot \mathrm{W}_{(k)} \\
& \mathrm{Q}_{c(k)}{ }^{A}=\frac{t_{v}}{t_{t}} \cdot \mathrm{Q}_{c(k)}
\end{aligned}
$$

where, $t_{v}$ is the vacuum time. 
The compression work and heat of condensation calculated from Eq. (31) and Eq. (33) are obtained assuming that all the reactors are simultaneously operated under vacuum. Allowing the reactors to be scheduled to start at different times reduces the maximum compression work $\left(\mathrm{W}_{(k)}{ }^{S}\right)$ and heat of condensation $\left(\mathrm{Q}_{c(k)}{ }^{S}\right)$ required in the cycle time. This, in turn, gives a reduction in the maximum size of the units and the investment costs. process may be calculated as,

$$
\begin{aligned}
& \mathrm{W}_{(k)}{ }^{s}=\mathrm{W}_{(k)} \cdot N_{V}^{M} / N_{R} \\
& \mathrm{Q}_{c(k)}{ }^{s}=\mathrm{Q}_{c(k)} \cdot N_{V}^{M} / N_{R}
\end{aligned}
$$

where $\left(N_{V}^{M} \leq N_{R}\right)$ is the maximum number of (the parallel) reactors that are operating under vacuum at any particular time. The value of $N_{V}^{M}$ may be obtained using a Gantt chart assuming that all the campaigns are operated in the same way, see Fig. 3. In this example, the total number of reactors is $N_{R}=12, t_{t}$ was $80 \mathrm{~h}$ and vacuum was applied after $28 \mathrm{~h}$, i.e. $t_{v}$ was $52 \mathrm{~h}$ (65\% of the total fermentation time). $N_{V}^{M}$ is a function of the time between the start-up of reactors $\left(t_{d}\right)$. If we specify a normalised time between the start-up of each reactor $\left(t_{d} / t_{t}\right)=0.05 \mathrm{~h} / \mathrm{h}$, it may be noted that for $N_{V}^{M}=$ 12 , there is no reduction in the amount of reactors simultaneously operating under vacuum (Fig. 3 Case A). However, when $\left(t_{d} / t_{t}\right)$ is specified as $0.1 \mathrm{~h} / \mathrm{h}$, then $N_{V}^{M}=9$ (Fig. 3 Case B). Therefore the adjustment (and optimisation of $t_{d}$ ) will give a lower $N_{V}^{M}$ and hence minimise $\mathrm{W}_{(k)}{ }^{S}$ and $\mathrm{Q}_{c(k)}{ }^{S}$. Similarly, $N_{V}^{M}$ is related to the vacuum time $\left(t_{v}\right)$, for example, if $t_{v}$ is reduced to $0.55 \mathrm{~h} / \mathrm{h}$ using $t_{d}$ equal to $0.1 \mathrm{~h} / \mathrm{h}, N_{V}^{M}$ is increased from 9 to 11 (Case C, Fig. 3). It is convenient to define the ratio between the average and the maximum compressor work or heat of condensation over the cycle time $\left(\mathrm{W}_{(k)}{ }^{S} / \mathrm{W}_{(k)}{ }^{A}\right.$ or $\mathrm{Q}_{c(k)}{ }^{S} / \mathrm{Q}_{c(k)}{ }^{A}$, respectively) as, 


$$
S_{M(k)}=\frac{\mathrm{W}_{(k)} s}{\mathrm{~W}_{(k)}{ }^{A}}=\frac{\mathrm{W}_{(k)} \cdot \frac{N_{V}^{M}}{N_{R}}}{\mathrm{~W}_{(k)} \cdot \frac{t_{v}}{t_{t}}}=\frac{t_{t}}{t_{v}} \cdot \frac{N_{V}^{M}}{N_{R}}
$$

363

364

365

366

367

This allows the Initial installation cost of compressors $\left(I_{C(k)}(U S D)\right)$ and the installation cost of each of the heat exchangers ( $I_{H X(k)}$ (USD)) (Kiran et al., 2012; Perkins, 2007) to be calculated in terms of $\mathrm{W}_{(k)}{ }^{A}$ and $\mathrm{Q}_{c(k)}{ }^{A}$,

$$
\begin{aligned}
& I_{C(k)}=4534 \cdot\left(\mathrm{W}_{(k)}{ }^{A} / 2\right)^{0.82} \cdot 2=4534 \cdot\left(\mathrm{W}_{(k)}{ }^{A} \cdot S_{M(k)} / 2\right)^{0.82} \cdot 2 \\
& I_{H X(k)}=21300 \cdot\left(\frac{\mathrm{Q}_{c(k)}{ }^{S}}{U \cdot L M T D}\right)^{0.65}=21300 \cdot\left(\frac{\mathrm{Q}_{c(k)}{ }^{A} \cdot S_{M(k)}}{U \cdot L M T D}\right)^{0.65}
\end{aligned}
$$

where, $U\left(1 \mathrm{MJ} / \mathrm{m}^{2} / \mathrm{K}\right)$ is the overall heat transfer coefficient and LMTD $(10 \mathrm{~K})$ is the

logarithmic mean temperature difference. As $U$ and $L M T D$ were asssumed constant a more rigourous estimation of these parameters must be performed in future work. To reduce the negative effect on the $E P$ in case of an eventual compressor failure during scheduled operation, it is assumed that two compressors (of half the size of that required) are used instead of only one compressor of full size (Eq. (41)).

\subsection{Cost estimation and process optimisation}

The aim is to maximise the $E P$ (USD/year) of the integrated reactor, where $E P$ is defined as,

$$
E P=\sum F_{A B E i} \cdot A B E_{i} \cdot t_{a}-O P E X-C A P E X
$$

where, $F_{A B E i}$ is the flow $(\mathrm{kg} / \mathrm{h})$ of the solvents (acetone, butanol and ethanol) produced in the fermentation, $A B E_{i}$ is the selling price of products (acetone, butanol and ethanol, Table 1).

The additional terms are the operating expense (OPEX) and the capital expenditures (CAPEX). Note that, during $A B E$ fermentation from lignocellulose, butyric acid, acetic acid, $\mathrm{H}_{2}$ and solids (residual lignocellulose and biomass) are produced as by-products. However, only ABE is considered as value added product.

The CAPEX (USD/year) is calculated as,

$$
C A P E X=\left(\sum I_{H X(k)}+\sum I_{C(k)}+I_{R} \cdot N_{R}\right) / t_{r i}
$$


Here $I_{R}$ is the installation cost of the reactors with $N_{R}$ being the number of reactors and $t_{r i}$ is the return time on the investment ( 3 years). A correlation that may be used to estimate the reactor installation cost $\left(I_{R}\right)$ as a function of the volume was reported by Oudshoorn et al., (2010) (Eq. (B-1) in Table 1). Correlations used to estimate $I_{H X(k)}$ and $I_{C(k)}$ were adapted from (Kiran et al., 2012; Perkins, 2007) (Eq. (41) and Eq. (42)).

The $O P E X$ (USD/year) is calculated as,

$$
O P E X=C_{C S} \cdot F_{0} \cdot w_{0(C S)}+C_{E Z} \cdot R_{E / C} \cdot F_{0} \cdot w_{0(C)}+\sum C_{E l} \cdot W_{(k)}^{\text {oper }} \cdot t_{a}+\sum C_{C W} \cdot Q_{C(k)}{ }^{o p e r} \cdot t_{a}
$$

In Eq. (45), the first term represents the operating costs associated with the use of corn stover, $w_{0(C S)}$ is the average load of corn stover (CS) on a dry basis in the feed, $F_{0}$ is the flow of corn stover on a mass basis $(\mathrm{kg} / \mathrm{h})$ and $C_{C S}$ is the cost of corn stover (USD/kg-dry-LCB). The second term represents the cost of enzymes required for the hydrolysis of cellulose, hence, $R_{E / C}$ is the ratio of enzyme to cellulose (g/g). The third and fourth terms in Eq. (45) represent the operating costs associated with the compressors (power, $W, \mathrm{kWh}$ ) and the heat exchangers (cold water, $Q_{c(k)}, \mathrm{MJ} / \mathrm{h}$ ), respectively. The numerical values of the various cost parameters are reported in the Table 1.

In order to maximise the $E P$ of the process, the genetic algorithm function 'ga' in Matlab was used. The variables that are adjusted during optimisation are the start-up time of the feed and the vacuum, the total time of reaction, initial concentration of cellulose in the reactor and in the continuous feed, the initial volume of fermentation, the enzyme load in the reactor and feeding stream, the vacuum pressure set-point, the pressure of the exit of compressors and the dilution rate. As the size of the heat exchanger and the compressor power depend on the pressure at the exit of compressors and operational times, these units are also optimised. Two constraints were imposed, a) non-soluble solids in the reactor must be lower than $100 \mathrm{~g} / \mathrm{l}$, and b) the concentration of corn stover in the continuous feed must be lower than 30 wt\% (composition of corn stover in the pretreatment (Humbird et al., 2011)). 


\subsection{Implementation aspects}

406 The annual production of ABE from corn stover was assumed to be 140,000 tonne/y. This gives

407 a corn stover capacity around 2,000 tonne/day (Humbird et al., 2011). The initial concentration of corn stover usually used for ethanol fermentation is shown in Table 2 (Humbird et al., 2011). These concentrations are used to define the ratio of compositions in reference to cellulose concentration in the feed, on a dry-basis. While, the initial concentration of cellulose in the reactor and the feed are variables to be determined via optimisation. volume (in this case, the total volume of the reactor broth was assumed to be at a maximum of $80 \%$ of the reactor volume). When ABE productivity is used to scale-up the reactor, the ratios of flow streams and reactor volume must be kept constant. As the volume of reactor does not affect the reaction rate (mass transfer resistances are not studied in this work), the productivity is constant with respect to the volume. Hence, the ABE productivity, $P_{A B E}$ $\left(\mathrm{kg} / \mathrm{h} / \mathrm{m}^{3}\right)$, was used as a basis for the scale-up of the reactor and this was defined as,

$$
P_{A B E}=\frac{\sum 1000 \cdot N_{(A B E)}^{t=t f} / M W(A B E)+\int_{t=0}^{t=t f} \sum\left(F_{P} \cdot x_{(0, A B E)}+F_{G(0)} \cdot y_{(0, A B E)}\right) \cdot d t}{\max \left(V_{T} / 0.8\right) \cdot t_{f}}
$$

where, $M W$ is the molecular weight $(\mathrm{g} / \mathrm{mol})$ of acetone, butanol and ethanol.

Given that all the reactors are assumed to be operated in the same way over the cycle time, only one reactor needs to be simulated reducing to some degree the computational effort. Therefore, the results of the simulation of a single reactor are used to calculate the $A B E$ productivity. The total volume of the reactors can then be found through $P_{A B E}$, the annual time of operation $\left(t_{a}\right)$ and the annual required production of $A B E(140,000$ tonne/y). As the reactors all have the same size and the maximum volume of each reactor was $3785 \mathrm{~m}^{3}$

427 (Humbird et al., 2011), the number of reactors $\left(N_{R}\right)$ that would be required to achieve the annual production target are found dividing the total volume of reactor(s) by $3785 \mathrm{~m}^{3}$. If $N_{R}$ is 
a decimal number, it is approximated to the next integer number and the volume of the reactor(s) is found dividing the total volume of reactor(s) by $N_{R}$. In this way, the volume of each reactor is lower than or equal to $3785 \mathrm{~m}^{3}$.

Having calculated the optimal reactor volume (and the total number of reactors required), the average work of the compressors and heat of exchangers are calculated. This allows the OPEX and CAPEX to be determined as well as the $E P$ given the particular set of decision variables. The optimisation algorithm then adjusts the values of the decision variables and the simulations are repeated iteratively until the maximum $E P$ is achieved.

\subsection{Results}

\subsection{Sizing of heat-pump system}

In this work, a short-cut method is used to calculate $S_{M(k)}$ which is developed through the analysis of several operating strategies using a range of the number of reactors and vacuum times (an automated generation of the Gantt charts). This repeated analysis of the effect of $t_{d}$ on the value of $S_{M(k)}$ is shown in Fig. 4 (a) which shows the minimum value of $S_{M(k)}$ (optimal $\left.t_{d}\right)$ for a range of values of parallel reactors $\left(N_{R}\right)$ and vacuum times $\left(t_{v}\right)$. It may be observed that very high number of reactors ( $>100)$ is necessary to totally minimise the variation in the value of $S_{M(k)}$. Furthermore, $S_{M(k)}$ may converge towards the minimum value of one (Fig. 4

(a)) for particular values of $t_{v}$ and the number of possible values of $t_{v}$ that make $S_{M(k)}$ converge to one increases with respect to $N_{R}$. In addition, small changes in $t_{v}$ can cause large variations in $S_{M(k)}$ passing through local maxima. For this reason, instead of a minimum value of $S_{M(k)}$, here, we used the average value $S_{M(k)}$ of all $t_{d}\left(t_{d}\right.$ between zero and $\left.t_{t}\right)$ in the optimisation. This average $S_{M(k)}$ (Fig. 4 (b)) depends only on the number of reactors and

451 vacuum operation, i.e. all the $t_{d}$ between 0 and $1 \mathrm{~h} / \mathrm{h}$ are used (and this will provide a conservative sizing of the units). 
As a short cut-method to estimate $S_{M}$, it was found that $S_{M}$ could be approximated with high

454 accuracy (Fig. 4 (b), $r^{2}>0.99$ ) using the following power law correlations,

$$
\begin{aligned}
& a_{1}=1.1174 \cdot N_{R}^{-0.021} \\
& a_{2}=1.4701 \cdot N_{R}^{-0.629} \\
& S_{M}=a_{1} \cdot t_{v}^{-a_{2}}
\end{aligned}
$$

455

456

457

458

The value of $S_{M}$ calculated using Eq. (49) is used to estimate $I_{C(k)}$ and $I_{H X(k)}$ using Eq. (41) and Eq. (42), respectively. The range of $t_{d}$ values that yield values of $S_{M}$ lower than that obtained using Eq. (49) are calculated after the optimisation was performed (to ensure valid optimisation results are obtained).

\subsection{Optimisation of operating strategies}

Despite the xylose inhibition on the enzymes, for batch process operation the concentration of solids in the reactor was found to be at the maximum limit $(100 \mathrm{~g} / \mathrm{l})$. This is probably because high concentrations of xylose and glucose are required for a faster growth of the biomass. The maximum concentration of active cells $(2.2 \mathrm{~g} / \mathrm{l})$ was achieved around $30 \mathrm{~h}$ (Fig $5(a))$.

The volume of reactor(s) was found to be the maximum $\left(3750 \mathrm{~m}^{3}\right)$ for all the operating strategies considered. The volume decreases from $80 \%$ to $62 \%$ of the total reactor volume due to water evaporation (Fig. 5 (a)). The reduction of the reactor volume indicates that fed-batch can be a superior operating mode because a higher amount of substrate can be fed. Hence, when the fed-batch operation mode was optimised, the volume decreased from 80 to $70 \%$ (Fig. 5 (b)). As a result, the EP increased when compared to batch operation by $1.3 \mathrm{MM}$ USD, Table 3. This was achieved by increasing the compressor work 1.22 -fold, reducing the enzyme load 1.27-fold and reducing the number of reactors from 12 to 10 . As with batch operation, it was found that the initial concentration of LCB (Fig. 5 (b)) was at the maximum bound (100 g-nonsoluble-solids/I). However, the average concentration of total dry-LCB in the feed was higher, around $20.3-21.7 \mathrm{wt} \%$ as opposed to $18.3 \mathrm{wt} \%$ (batch process), see Table 3, this was because 
the feed stream used a higher substrate concentration (optimisation variable) (Fig. 1). This average concentration of LCB was similar to that used in ethanol production by simultaneous co-fermentation and saccharification (20.9 wt\%, Table 2).

The energy requirements of the heat-pump system for the batch process were found to be the lowest at a higher vacuum pressure ( 0.052 bar) and lower vacuum operational times (73.1 $\%$ of the cycle time). It was also found to be related to productivity, where a low rate of recovery of butanol decreases the energy requirement. These results are consistent with the results reported for gas stripping by Lodi et al., (2018).

In the batch process the productivity is limited by substrate availability because substrate is only fed at the start of the fermentation. Hence, it was more difficult to obtain an incremental improvement in the productivity or a reduction in enzyme load in batch process operation than a reduction in the energy requirements.

It is known that the highest productivity is achieved using continuous operation (Tao et al., 2014). These results are consistent with the results obtained in this work as the lowest number of reactors was obtained for continuous operation (8 reactors, see Table 3). However, due to the high energy requirements, the high enzyme load and low yield, continuous operation was found to be the least attractive choice both in terms of economics and energy usage, i.e. continuous operation had the highest energy requirements and the lowest $E P$.

\subsection{Total energy requirements}

The effect on the $E P$ and the total compression work as a function of the number of stages of compression and isentropic efficiency is shown in Fig. 6. Using three stages of compression, the $E P$ is reduced $18 \%$ if $\eta_{s}$ is fixed at 0.55 instead at 0.75 . The compression work reduces $28-30 \%$ if the number of stages is two instead of one. When the number of stages of compression was increased from two to three, the total compression work reduced between 8.4 and $9.6 \%\left(\eta_{s}\right.$ between 0.55 and 0.75$)$. Three stages was found to give the optimal $E P\left(\eta_{s}=\right.$ 
501 0.75). However, the EP was only reduced 2-3\% because the investment in the compressor

502 increases as well, i.e. more compressors and heat exchangers are required.

$$
\eta_{s}=0.1058 \cdot \ln \left(\frac{P_{k-1}}{P_{k}}\right)+0.8746
$$

504

505

506

507

508

509

510

511

512

513

514

515

516

517

518

519

520

521

522

When Eq. (50) was used to estimate $\eta_{s}$ the $E P$ using three stages was similar than obtained when fixing $\eta_{s}$ equal to 0.75 as the compression ratio $P_{k-1} / P_{k}$ achieved in the optimisation (between 0.25 and 0.4 ) gives $\eta_{s}$ between 0.73 and 0.78 . Whilst, when the number of stages of compression was one $\left(P_{k-1} / P_{k} \cong 0.05\right), \eta_{s}$ was reduced to 0.55 . In this sense, the isentropic efficiency increases with the number of stages of compression.

The total energy requirements of the ISPR by vacuum evaporation depends on both the compression costs and the final purification system - which is performed by double-effect distillation (DED) (Grisales Diaz and Olivar Tost, 2018). Therefore, after the optimal conditions of the reactor were obtained the reactor and final separation system were simulated in Aspen Plus $\mathrm{V}^{\circ}$ in order to find the total energy requirements for the system and to validate the dynamic modelling results. Due to the dynamic operating conditions, the complex kinetics and the in situ recovery, the ISPR-V cannot be simulated in one process unit of Aspen Plus V9 ${ }^{\circ}$. Hence, the ISPR was simulated in Aspen Plus $\mathrm{V}^{\circ}$ continuous mode combining a 'stoic reactor' followed by the ideal separator 'Sep' (using the vacuum recovery rates from Matlab ${ }^{\circledR}$ simulations) and the flash unit 'Flash2' (operating at atmospheric pressure). The differences in the compression work between those of the Matlab 2016. $a^{\circ}$ and the Aspen Plus V9 ${ }^{\circ}$ simulations were around $2.8 \%$ (results not shown).

The energy requirements of the final purification by DED were mainly a function of $A B E$ yield, substrate concentration, and $A B E$ recovery in the gas stream. The energy requirements of DED for the fed-batch process were the lowest, (3.45 MJ/kg ABE). However, batch operation had the lowest total energy requirement (9.6 MJ fuel/kg ABE, Table 3). Indeed, it was found that the energy requirements, when compared to continuous operation, were reduced by between 21 

and $28 \%$ using fed-batch and batch operating systems. Mariano et al., (2011) reported an energy requirement for continuous operation of $13.4 \mathrm{MJ} / \mathrm{Kg}$ butanol, which was lower than that reported for batch, $>22 \mathrm{MJ} / \mathrm{Kg}$ butanol. Our results differ as the substrate concentration used by Mariano et al., (2012a) in the evaluation of batch operation was 2.5 lower. In addition, the final butanol concentration in the reactor for batch and continuous operation were $\sim 2 \mathrm{~g} / \mathrm{l}$ and $\sim 10 \mathrm{~g} / \mathrm{l}$, respectively. A higher butanol concentration decreases the energy requirements as the butanol concentration in the gas stream increases.

The total compressor work was found to be between 1.8 and $2.9 \mathrm{MJ} / \mathrm{kg} \mathrm{ABE}$ or between 2.4 and $3.4 \mathrm{MJ} / \mathrm{kg}$ butanol. In contrast, the energy requirements of compression reported by Mariano et al., (2011) for continuous vacuum fermentation were between 4.4 and $6.5 \mathrm{MJ} / \mathrm{kg}$ butanol. In this paper, the total compressor work was around 1.3 and 1.9-fold lower than that reported by Mariano et al., (2011) as three compression stages operating under optimal conditions were used and the excess heat was not used to supply heat required for the distillation system.

In the literature, alternative processes for vacuum recovery have been proposed for butanol production. Of all the alternatives considered liquid-liquid extraction, adsorption and pervaporation have been reported with the lowest energy requirements (between 7 and 10.9 MJ fuel/kg ABE (Grisales Díaz and Olivar Tost, 2016a; Qureshi et al., 2005)). In comparison, the energy requirements of the processes studied in this paper for batch and fed-batch operation were between 9.6 and $10.5 \mathrm{MJ}$ fuel/kg ABE. Hence, batch and fed-batch operation of vacuum fermentation compares favourably with alternative technologies.

\subsection{Conclusions}

The $E P$ of three operating modes (batch, fed-batch and continuous) have been investigated. A heat-pump using a three stage compression system with partial condensation was used to minimise the energy requirements. The operating variables of the reactor (fermentation time, substrate concentrations, initial volume, enzyme load, vacuum times, dilution rate and 
553 and two in the series) were optimised. Based upon the dynamic model used and the

554 estimation of both capital and operating costs it was found that a) batch process operation

555 achieved the lowest energy requirements (9.6 MJ fuel/kg ABE) because the butanol

556 concentration in the reactor was the highest ( $5.8 \mathrm{~g} / \mathrm{l}$ at the end of fermentation) b) a

557 continuous process would have the lowest EP (23.6 MM USD) and the highest energy

558 requirements (13.6 $\mathrm{MJ}$ fuel $/ \mathrm{kg} \mathrm{ABE}$ ), due to the low $\mathrm{ABE}$ yield and that $\mathrm{c}$ ) fed-batch operation

559 was the most profitable (37.6 MM USD) because a higher productivity was achieved in

560 comparison with batch fermentation.

561 The process flowsheet considered in this work assumed that the multiple reactors required to

562 achieve the target productivity were all operated in parallel. However, it was demonstrated

563 that the capital investment required of the heat-pump system may be minimised through the

564 scheduling of reactor operation (sequencing the start-up time of the reactors). The optimal

565 scheduling of the reactors combined with the proposed energy integration scheme gave

566 process energy requirements that are similar to that achieved by units with low energy

567 requirements.

568 The energy requirements are strongly dependent on the reactor operating conditions, hence,

569 for a fair comparison is recommended that the energy analysis of the integrated reactors must

570 be made using their optimal $E P$.

571 Appendix

Table A1

Biochemical reaction rates

\begin{tabular}{|c|c|c|c|}
\hline Rate term & Eq. & Rate term & Eq. \\
\hline$r_{1}=\frac{V_{\max }[\text { Glucose }][\text { Biomass }]}{K m_{1}+[\text { Glucose }]} \cdot l_{B}^{n_{1}} \cdot F$ & $(1-K)$ & $r_{10}=\frac{V_{\max 10}[A A C O A][\text { Biomass }]}{K m_{1}+[A A O A A]}$. & $(11-K)$ \\
\hline$r_{2}=\frac{V_{\max 2}[\text { Pyruvate }][\text { Biomass }]}{\text { Km }]+[\text { Pyruvate }]} \cdot F$ & $(2-K)$ & $r_{11}=\frac{V_{\max 11}[\text { AACoA }][\text { Butyrate }][\text { Biomass }]}{\left([\text { AACoA }]+K m b_{11}\right)\left([\text { Butyrate }]+K m a_{11}\right)} \cdot I_{B}^{n 11}$ & $(12-K)$ \\
\hline$r_{3}=\frac{V_{\text {max }}[\text { [Acetate }][\text { Biomass }]}{\text { Km }_{3}+[\text { Acetate }]} \cdot F \cdot I_{B}^{n 3}$ & $(3-K)$ & 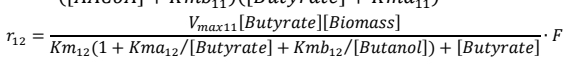 & $(13-K)$ \\
\hline$r_{4}=\frac{V_{\text {max }_{4}}[\text { Acetate }][\text { AACoA }][\text { Biomass }]}{\left(\text { Kma }_{4}+[\text { Acetate }]\right) \cdot\left(\mathrm{Kmb}_{4}+[\text { AACOA }]\right)} \cdot F \cdot I_{B}^{n 4}$ & $(4-K)$ & $r_{13}=\frac{V_{\max 13}[B C o A][\text { Biomass }]}{K m_{13}+[B C O A]} \cdot F$ & $(14-K)$ \\
\hline$r_{6}=\frac{V_{\max }[\text { ACoA][Biomass }]}{K m_{1}+\left[A C_{0} A\right]} \cdot F \cdot I_{B}^{n 6}$ & $(6-K)$ & $r_{14}=\frac{V_{\max 14}[\text { BCoA] }][\text { Biomass }]}{K m_{1}\left(1+K m a_{14} /[\text { Butyrate })+[B C o A]\right.} \cdot F$ & $(15-K)$ \\
\hline$r_{7}=\frac{V_{\max }[\text { ACoA }][\text { Biomass }]}{K m_{7}+[\text { ACoA }]} \cdot F$ & $(7-K)$ & $r_{15}=\frac{V_{\max 15}[\text { Xylose }][\text { Biomass }]}{K m_{15}+[\text { Xylose }]} F \cdot I_{B}^{n 15}$ & $(16-K)$ \\
\hline$r_{8}=\frac{V_{\max 8}[\text { [Glucose }][\text { Biomass }]}{K m_{8}\left(1+K m a_{8} /[\text { [BoA }]\right)+[\text { Glucose }]} \cdot I_{N H}$ & $(8-K)$ & $r_{16}=\frac{V_{\max 16}[\text { [ylose }]}{K m_{16}\left(1+K m a_{16} /[\text { BCoA }]\right)+[\text { Xylose }]} F \cdot I_{N H}$ & $(17-K)$ \\
\hline
\end{tabular}




$$
\begin{aligned}
& r_{9}=V_{\max 9}[\text { Biomass }] \\
& I_{B}=\left(1-\frac{[\text { Butanol }]}{[\text { Bumax }]}\right) \\
& r_{17}=V_{\max 17}[\text { Biomass }] \\
& \omega=\left(\frac{[\text { Glucose }]}{[\text { Glucose }]+[\text { Xylose }]}\right) \\
& I_{N H}=\left(1-\frac{[\text { Acetate }]}{[\text { Acemax }]}\right)\left(1-\frac{[\text { butyrate }]}{[\text { Butmax }]}\right)\left(1-\frac{[\text { Biomass }]+[\text { Biomass dead }]}{[\text { Bimax }]}\right)\left(1-\frac{[\text { Glucose }]}{[\text { Glumax }]}\right)\left(1-\frac{[\text { Xylose }]}{[\text { Xymax }]}\right) \cdot I_{B}{ }^{n 19} \\
& \mathrm{r}_{W 1}=\frac{k_{1 r} \cdot E_{1 B} \cdot R_{C} \cdot[\text { Cellulose }]}{1+\frac{[\text { [ellubiose }]}{K_{1 G 2}}+\frac{[\text { Glucosem }]}{K_{11 G}}+\frac{[\text { Xylosem }]}{K_{11 x}}} \\
& \begin{array}{c}
K_{11 G 2}+K_{1 I G}+K_{21 x} \\
k_{2 r} \cdot\left(E_{1 B}+E_{2 B}\right) \cdot R_{C} \cdot[\text { Cellulose }]
\end{array} \\
& \mathrm{r}_{w 2}=\frac{[\text { [Cellubiose }]}{K_{2 B}}+\frac{[\text { Glucosem }]}{K_{2}}+\frac{[\text { Xylosem }]}{K_{21 X}} \\
& \mathrm{r}_{w 3}=\frac{k_{3 r} \cdot E_{2 F} \cdot R_{C} \cdot[\text { Cellubiose }]}{K_{3 M}\left(1+\frac{[\text { Glucosem }]}{K_{3 I G}}+\frac{[\text { Xylosem }]}{K_{31 X}}\right)+[\text { Cellubiose }]} \\
& E_{i B}=\frac{E_{\text {imax }} \cdot K_{\text {iad }} \cdot E_{i F} \cdot S}{1+K_{\text {iad }} \cdot E_{i F}}, i=1,2
\end{aligned}
$$

\begin{tabular}{|c|c|c|c|c|c|}
\hline Reaction & Vmax & $\mathrm{Km}$ & $\mathrm{Km}_{\mathrm{a}}$ & $\mathrm{Km}_{\mathrm{b}}$ & $\mathrm{n}$ \\
\hline$r_{1}$ & 1.16 & 0.05 & $4 \times 10^{12}$ & & 1 \\
\hline$r_{2}$ & 33.1 & 17.5 & & & \\
\hline$r_{3}$ & 0.84 & 113 & & & 1 \\
\hline$r_{4}$ & 34.1 & & 198 & 8.4 & 2.75 \\
\hline$r_{6}$ & 2.46 & 0.001 & & & 1 \\
\hline$r_{7}$ & 50.4 & 2.24 & & & \\
\hline$r_{8}$ & 0.92 & 83.7 & 0.0013 & & \\
\hline$r_{9}$ & 0.034 & & & & \\
\hline$r_{10}$ & 59.8 & 3.6 & & & \\
\hline$r_{11}$ & 0.23 & & 0.062 & 0.002 & $1^{\mathrm{a}}$ \\
\hline$r_{12}$ & 38.3 & 1.36 & 113 & 679.3 & \\
\hline$r_{13}$ & 6.18 & 2.06 & & & \\
\hline$r_{14}$ & 146 & 3.65 & 520 & & \\
\hline$r_{15}$ & 1.72 & 0.248 & & & 0.52 \\
\hline$r_{16}$ & 0.14 & 1.47 & 14.02 & & \\
\hline$r_{17}$ & 0.0088 & & & & \\
\hline \multicolumn{6}{|c|}{ Additional parameters of the metabolic kinetic model } \\
\hline Parameter & & Parameter & & Parameter & \\
\hline [Bumax] & 210.7 & [Acmax] & 142.3 & [Butmax] & 87.48 \\
\hline [Bimax] & 581 & [Glumax] & 916 & $\mathrm{ng} / \mathrm{x}$ & 0.096 \\
\hline [Xymax] & 3367 & $\mathrm{n}_{19}$ & 1.73 & & \\
\hline
\end{tabular}

Table A2

Model parameters of the kinetic model of fermentation $A B E$

a $\mathrm{n} 11$ is equal to 0.068 if [Butanol] $<11.6 \mathrm{~g} / \mathrm{l}$

$\mathrm{Km}, \mathrm{kma}, \mathrm{kmb}$ are constants of the kinetic model (mmol/l); Vmax, maximum rate of reaction (h-1);

$\mathrm{n}$, power term of inhibition (-); [Acemax], total inhibition concentration of acetone (mmol/l); [Acmax], total inhibition concentration of acetate $(\mathrm{mmol} / \mathrm{l})$; [Bimax], total inhibition concentration of butanol (mmol/l); [Bumax], total inhibition concentration of butyrate ( $\mathrm{mmol} / \mathrm{l})$; [Glumax] total inhibition concentration of glucose $(\mathrm{mmol} / \mathrm{l})$; [Xymax] total inhibition concentration of xylose $(\mathrm{mmol} / \mathrm{l})$ 
Table A3

Parameters of the sacharification model*

\begin{tabular}{|c|c|c|c|}
\hline Parameter & Value & Parameter & Value \\
\hline $\mathrm{K}_{1 \mathrm{ad}}$ & 0.4 & $k_{2 r}$ & 7.18 \\
\hline $\mathrm{K}_{2 \mathrm{ad}}$ & 0.1 & $\mathrm{~K}_{2 \mid \mathrm{G} 2}$ & 132 \\
\hline $\mathrm{E}_{1 \max }$ & 0.06 & $\mathrm{~K}_{21 \mathrm{G}}$ & 0.04 \\
\hline$E_{2 \max }$ & 0.01 & $\mathrm{~K}_{21 \mathrm{X}}$ & 0.2 \\
\hline$E_{a}$ & -23179 & $k_{3 r}$ & 285.5 \\
\hline $\mathrm{k}_{1 \mathrm{r}}$ & 22.3 & $\mathrm{~K}_{3 \mathrm{M}}$ & 24.3 \\
\hline $\mathrm{K}_{1 \mid \mathrm{G} 2}$ & 0.015 & $K_{31 G}$ & 3.9 \\
\hline $\mathrm{K}_{1 \mid \mathrm{G}}$ & 0.1 & $\mathrm{~K}_{31 \mathrm{X}}$ & 201 \\
\hline $\mathrm{K}_{1 \mathrm{IX}}$ & 0.1 & & \\
\hline \multicolumn{4}{|c|}{$\begin{array}{l}\text { Kad, dissociation term for the enzyme (g protein } / \mathrm{g} \\
\text { cellulose); KilG, inhibition terms for glucose }(\mathrm{g} / \mathrm{kg}) ; \mathrm{KilG} 2 \text {, } \\
\text { inhibition terms for cellobiose }(\mathrm{g} / \mathrm{kg}) ; \mathrm{kir} \text {, reaction rate } \\
\text { terms }(\mathrm{kg} / \mathrm{g} / \mathrm{h}) ; \mathrm{KilX} \text {, inhibition terms for xylose }(\mathrm{g} / \mathrm{kg}) ; \mathrm{K} 3 \mathrm{M} \text {, } \\
\text { cellobiose saturation term }(\mathrm{g} / \mathrm{kg}) ; \text { Ea, activation energy } \\
(\mathrm{J} / \mathrm{mol}) ; \text { Emax, maximum amount of the enzyme that can } \\
\text { adsorb onto of substrate (g protein/ g cellulose); }\end{array}$} \\
\hline
\end{tabular}

575

Funding

579 This research did not receive any specific grant from funding agencies in the public,

580 commercial, or not-for-profit sectors.

\section{References}

582 Abdi, H.K., Alanazi, K.F., Rohani, A.S., Mehrani, P., Thibault, J., 2016. Economic comparison of a continuous $A B E$ fermentation with and without the integration of an in situ vacuum separation unit. Can. J. Chem. Eng. 94, 833-843. doi:10.1002/cjce.22461

Belaissaoui, B., Le Moullec, Y., Favre, E., 2016. Energy efficiency of a hybrid air: A generic approach. Energy 95, 291-302. doi:10.1016/j.energy.2015.12.006 
Claes, S., Vandezande, P., Mullens, S., De Sitter, K., Peeters, R., Van Bael, M.K., 2012. Preparation and benchmarking of thin film supported PTMSP-silica pervaporation membranes. J. Memb. Sci. 389, 265-271. doi:10.1016/j.memsci.2011.10.035

Dubreuil, M.F.S., Vandezande, P., Van Hecke, W.H.S., Porto-Carrero, W.J., Dotremont, C.T.E., 2013. Study on ageing/fouling phenomena and the effect of upstream nanofiltration on in-situ product recovery of n-butanol through poly[1-(trimethylsilyl)-1-propyne] pervaporation membranes. J. Memb. Sci. 447, 134-143. doi:10.1016/j.memsci.2013.07.032

Fontalvo, J., Cuellar, P., Timmer, J.M.K., Vorstman, M.A.G., Wijers, J.G., Keurentjes, J.T.F., 2005. Comparing pervaporation and vapor permeation hybrid distillation processes. Ind. Eng. Chem. Res. 44, 5259-5266. doi:10.1021/ie049225z

Ghosh, S., Chowdhury, R., Bhattacharya, P., 2017. Sustainability of cereal straws for the fermentative production of second generation biofuels: A review of the efficiency and economics of biochemical pretreatment processes. Appl. Energy 198, 284-298. doi:10.1016/j.apenergy.2016.12.091

Grisales Diaz, V.H., Olivar Tost, G., 2018. Energy efficiency of acetone, butanol, and ethanol (ABE) recovery by heat-integrated distillation. Bioprocess Biosyst. Eng. 41, 395-405. doi:10.1007/s00449-017-1874-z

Grisales Díaz, V.H., Olivar Tost, G., 2016a. Butanol production from lignocellulose by simultaneous fermentation, saccharification, and pervaporation or vacuum evaporation. Bioresour. Technol. 218, 174-182. doi:10.1016/j.biortech.2016.06.091

Grisales Díaz, V.H., Olivar Tost, G., 2016b. Ethanol and isobutanol dehydration by heatintegrated distillation. Chem. Eng. Process. Process Intensif. 108, 117-124. doi:10.1016/j.cep.2016.07.005

Grisales Díaz, V.H., Willis, M.J., 2018. Kinetic modelling and simulation of batch, continuous and cell-recycling fermentations for acetone-butanol-ethanol production using 

doi:10.1016/j.bej.2018.05.011

Henley, E., Seader, J., Roper, D., 2011. Separation process principles: chemical and biochemical operations, John Wiley. ed.

Hodge, D.B., Karim, M.N., Schell, D.J., McMillan, J.D., 2008. Soluble and insoluble solids contributions to high-solids enzymatic hydrolysis of lignocellulose. Bioresour. Technol. 99, 8940-8948. doi:10.1016/j.biortech.2008.05.015

Humbird, D., Davis, R., Tao, L., Kinchin, C., Hsu, D., Aden, A., Schoen, P., Lukas, J., Olthof, M., Worley, M., Sexton, D., Dudgeon, D., 2011. Process Design and Economics for

Kadam, K.L., Rydholm, E.C., McMillan, J.D., 2004. Development and validation of a kinetic model for enzymatic saccharification of lignocellulosic biomass. Biotechnol. Prog. 20, 698-705. doi:10.1021/bp034316x

Kiran, B., Jana, A.K., Samanta, A.N., 2012. A novel intensified heat integration in multicomponent distillation. Energy 41, 443-453. doi:10.1016/j.energy.2012.02.055

Kujawska, A., Kujawski, J., Bryjak, M., Kujawski, W., 2015. ABE fermentation products recovery methods-A review. Renew. Sustain. Energy Rev. 48, 648-661. doi:10.1016/j.rser.2015.04.028

Lodi, G., De Guido, G., Pellegrini, L.A., 2018. Simulation and energy analysis of the ABE fermentation integrated with gas stripping. Biomass and Bioenergy 116, 227-235. doi:10.1016/j.biombioe.2018.06.012

Mariano, A.P., Filho, R.M., Ezeji, T.C., 2012a. Energy requirements during butanol production and in situ recovery by cyclic vacuum. Renew. Energy 47, 183-187. doi:10.1016/j.renene.2012.04.041

Mariano, A.P., Keshtkar, M.J., Atala, D.I.P., Maugeri Filho, F., Wolf Maciel, M.R., Maciel Filho, R., Stuart, P., 2011. Energy requirements for butanol recovery using the flash 
Mariano, A.P., Qureshi, N., Maciel Filho, R., Ezeji, T.C., 2012b. Assessment of in situ butanol recovery by vacuum during acetone butanol ethanol (ABE) fermentation. J. Chem. Technol. Biotechnol. 87, 334-340. doi:10.1002/jctb.2717

Matsumiya, N., Teramoto, M., Kitada, S., Matsuyama, H., 2005. Evaluation of energy consumption for separation of $\mathrm{CO} 2$ in flue gas by hollow fiber facilitated transport membrane module with permeation of amine solution. Sep. Purif. Technol. 46, 26-32. doi:10.1016/j.seppur.2005.04.006

Milestone, N.B., Bibby, D.M., 1981. Concentration of alcohols by adsorption on silicalite. J. Chem. Technol. Biotechnol. 31, 732-736. doi:10.1002/jctb.503310198

Morales-Rodriguez, R., Gernaey, K. V., Meyer, A.S., Sin, G., 2011. A Mathematical Model for Simultaneous Saccharification and Co-fermentation (SSCF) of C6 and C5 Sugars. Chinese J.

Mussatto, S.I., Moncada, J., Roberto, I.C., Cardona, C. a., 2013. Techno-economic analysis for Chem. Eng. 19, 185-191. doi:10.1016/S1004-9541(11)60152-3 brewer's spent grains use on a biorefinery concept: The Brazilian case. Bioresour. Technol. 148, 302-310. doi:10.1016/j.biortech.2013.08.046

Oudshoorn, A., van den Berg, C., Roelands, C.P.M., Straathof, A.J.J., van der Wielen, L. a. M., 2010. Short-cut calculations for integrated product recovery options in fermentative production of bio-bulk chemicals. Process Biochem. 45, 1605-1615.

doi:10.1016/j.procbio.2010.07.003

Oudshoorn, A., van der Wielen, L.A.M., Straathof, A.J.J., 2009. Assessment of Options for Selective 1-Butanol Recovery from Aqueous Solution. Ind. Eng. Chem. Res. 48, 73257336. doi:10.1021/ie900537w

Pereira, J.P.C., Lopez-Gomez, G., Reyes, N.G., van der Wielen, L.A.M., Straathof, A.J.J., 2017. Prospects and challenges for the recovery of 2-butanol produced by vacuum fermentation - a techno-economic analysis. Biotechnol. J. 12, 1600657. 
671 Perkins, J.D., 2007. Conceptual design of chemical processes J. M. Douglas, McGraw-Hill, New York, 1988. J. Chem. Technol. Biotechnol. 46, 249-249. doi:10.1002/jctb.280460308

Quiroz-Ramírez, J.J., Sánchez-Ramírez, E., Segovia-Hernández, J.G., 2018. Energy, exergy and techno-economic analysis for biobutanol production: a multi-objective optimization approach based on economic and environmental criteria. Clean Technol. Environ. Policy. doi:10.1007/s10098-018-1486-6

677

Qureshi, N., Hughes, S., Maddox, I.S., Cotta, M. a, 2005. Energy-efficient recovery of butanol from model solutions and fermentation broth by adsorption. Bioprocess Biosyst. Eng. 27, 215-22. doi:10.1007/s00449-005-0402-8

Qureshi, N., Singh, V., Liu, S., Ezeji, T.C., Saha, B.C., Cotta, M.A., 2014. Process integration for simultaneous saccharification, fermentation, and recovery (SSFR): Production of butanol

Raganati, F., Procentese, A., Olivieri, G., Russo, M.E., Gotz, P., Salatino, P., Marzocchella, A., 2016. Butanol production by Clostridium acetobutylicum in a series of packed bed biofilm reactors. Chem. Eng. Sci. 152, 678-688. doi:10.1016/j.ces.2016.06.059

Ren, C., Gu, Y., Hu, S., Wu, Y., Wang, P., Yang, Y., Yang, C., Yang, S., Jiang, W., 2010. Identification and inactivation of pleiotropic regulator CcpA to eliminate glucose repression of xylose utilization in Clostridium acetobutylicum. Metab. Eng. 12, 446-454. doi:10.1016/j.ymben.2010.05.002

Sander, R., 2015. Compilation of Henry's law constants (version 4.0) for water as solvent. Atmos. Chem. Phys. 15, 4399-4981. doi:10.5194/acp-15-4399-2015

Servinsky, M.D., Kiel, J.T., Dupuy, N.F., Sund, C.J., 2010. Transcriptional analysis of differential carbohydrate utilization by Clostridium acetobutylicum. Microbiology 156, 3478-3491. doi:10.1099/mic.0.037085-0 
Sharif Rohani, A., Mehrani, P., Thibault, J., 2015. Comparison of in-situ recovery methods of gas stripping, pervaporation, and vacuum separation by multi-objective optimization for producing biobutanol via fermentation process. Can. J. Chem. Eng. 93, 986-997. doi:10.1002/cjce.22186

Sreemahadevan, S., Singh, V., Roychoudhury, P.K., Ahammad, S.Z., 2018. Mathematical modeling, simulation and validation for co-fermentation of glucose and xylose by Saccharomyces cerevisiae and Scheffersomyces stipitis. Biomass and Bioenergy 110, 1724. doi:10.1016/j.biombioe.2018.01.008

Tao, L., He, X., Tan, E.C.D., Zhang, M., Aden, A., Renewable, N., 2014. Comparative technoeconomic analysis and reviews of $n$-butanol production from corn grain and corn stover. Biofuels, Bioprod. Bioref. 8, 342-361. doi:10.1002/bbb.1462

Vane, L.M., Alvarez, F.R., Rosenblum, L., Govindaswamy, S., 2013. Hybrid vapor stripping-vapor permeation process for recovery and dehydration of 1-butanol and acetone/butanol/ethanol from dilute aqueous solutions. Part 2. Experimental validation with simple mixtures and actual fermentation broth. J. Chem. Technol. Biotechnol. 88, 1436-1447. doi:10.1002/jctb.4086

Xue, C., Liu, F., Xu, M., Tang, I.C., Zhao, J., Bai, F., Yang, S.T., 2016. Butanol production in acetone-butanol-ethanol fermentation with in situ product recovery by adsorption. Bioresour. Technol. 219, 158-168. doi:10.1016/j.biortech.2016.07.111

Xue, C., Zhao, J.B., Chen, L.J., Bai, F.W., Yang, S.T., Sun, J.X., 2014. Integrated butanol recovery for an advanced biofuel: Current state and prospects. Appl. Microbiol. Biotechnol. 98, 3463-3474. doi:10.1007/s00253-014-5561-6

Xue, C., Zhao, X.-Q., Liu, C.-G., Chen, L.-J., Bai, F.-W., 2013. Prospective and development of butanol as an advanced biofuel. Biotechnol. Adv. 31, 1575-84. doi:10.1016/j.biotechadv.2013.08.004

Yao, D., Dong, S., Wang, P., Chen, T., Wang, J., Yue, Z.B., Wang, Y., 2017. Robustness of 

of lignocellulosic sugars and inhibitors. Fuel 208, 549-557. doi:10.1016/j.fuel.2017.07.004

Yaws, C.L., Satyro, M.A., 2009. Enthalpy of vaporization-Organic compounds, in: Thermophysical Properties of Chemicals and Hydrocarbons. Elsevier, pp. 309-400. doi:10.1016/B978-081551596-8.50012-2

727 Zauba, 2015. India's import and export data. https://www.zauba.com/.

728

Zheng, J., Tashiro, Y., Wang, Q., Sonomoto, K., 2015. Recent advances to improve fermentative

731

732

733

734

735

736

737

738

739

740

741

742

743

744

745

746 
Table 1

Cost parameters for ABE production from corn stover

\begin{tabular}{llll}
\hline Parameters & Units & Value & Eq. \\
\hline Water cooling cost (Mussatto et al., 2013) & USD/MJ & $2.3 \times 10^{-4}$ & \\
Enzyme cost (Mussatto et al., 2013) & USD/kg-protein & 4.24 \\
Corn stover cost (Tao et al., 2014) & USD/kg-dry-LCB & 0.064 \\
Electricity cost (Mussatto et al., 2013) & USD/kWh & 0.1 \\
Selling cost of butanol (Zauba, 2015) & USD/kg & 1.0 \\
Selling cost of ethanol (Zauba, 2015) & USD/kg & 0.8 \\
Selling cost of acetone (Zauba, 2015) & USD/kg & 0.7 & (B-1) \\
Initial installation cost of reactors $\left(I_{R}\right)^{\text {a }}$ (Oudshoorn & USD & $27846 \cdot V_{R}^{0.61}+151967$ & \\
et al., 2010) & & & \\
\hline
\end{tabular}

750

$V_{R}\left(m^{3}\right)$ is the volume of reactor; ${ }^{a}$ conversion factor of EURO to USD was 1.37

751

752

753

754

755

756

757

758

759

760

761

762

763

764

765

766

767 
Table 2

Characterization of corn stover

\begin{tabular}{ll}
\hline Component & Composition (w/w) \\
\hline Xylose (SS) & 0.047 \\
Cellulose (IS) & 0.061 \\
Glucose (SS) & 0.008 \\
Other SS:IS (1:1) & 0.093 \\
Total & 0.209 \\
\hline SS, soluble solids, IS, insoluble solids. Other: lignin, \\
ash, ammonia, etc. \\
\hline a Initial concentration used for isobutanol or ethanol \\
production by a simultaneous saccharification and \\
fermentation system (Humbird et al., 2011; Tao et \\
al., 2014))
\end{tabular}

769

770

771

772

773

774

775

776

777

778

779

780

781

782

783

784

785

786

787 
Table 3

The effect of operational mode on the performance of ABE production by ISPR-V

\begin{tabular}{lccc}
\hline \multirow{2}{*}{ Item } & \multicolumn{3}{c}{ Operation mode } \\
\cline { 2 - 4 } & Batch & Fed-batch & Continuous \\
\hline ABE yield (g/g) & 0.391 & 0.39 & 0.305 \\
Butanol yield (g/g) & 0.299 & 0.305 & 0.247 \\
Cellulose conversion (\%) & 87.3 & 85.5 & 53.2 \\
Xylose conversion (\%) & 99.9 & 99.3 & 82.6 \\
Cycle time (h) & 88.2 & 103.2 & 504 \\
\% of vacuum in the cycle time & 73.1 & 78.9 & 99.2 \\
$S_{M}$ & 1.17 & 1.16 & 1.08 \\
Vacuum pressure (bar) & 0.052 & 0.05 & 0.047 \\
Butanol recovery (g/g \%) & 85.8 & 90.6 & 89.2 \\
Enzyme load (g-protein/kg-cellulose) & 12.7 & 10.2 & 8.5 \\
Avg. LCB in the feeding (wt. \%) & 18.3 & 20.3 & 18.3 \\
Final butanol concentration in the reactor (g/l) & 5.8 & 4.8 & 3.6 \\
Number of reactors & 12 & 10 & 8 \\
Compression work (MJ/kg-ABE) & 1.8 & 2.2 & 2.87 \\
Energy consumption of distillation (MJ/kg-ABE) & 3.7 & 3.45 & 4.14 \\
Total energy requirements (MJ-fuel/kg-ABE) ${ }^{\mathrm{d}}$ & 9.6 & 10.5 & 13.3 \\
EP (MM USD/y) & 36.6 & 37.8 & 23.6 \\
\hline
\end{tabular}

${ }^{a}$ Including ethanol dehydration requirements by a heat-integrated distillation system (Grisales Díaz and Olivar Tost, 2016b)

$\mathrm{b}$ the fuel requirements were calculated assuming an efficiency of electricity and steam production from fuel of 0.9 and 0.33 , respectively. These included the ABE recovery by the total recovery system ( $\sim .98)$ 


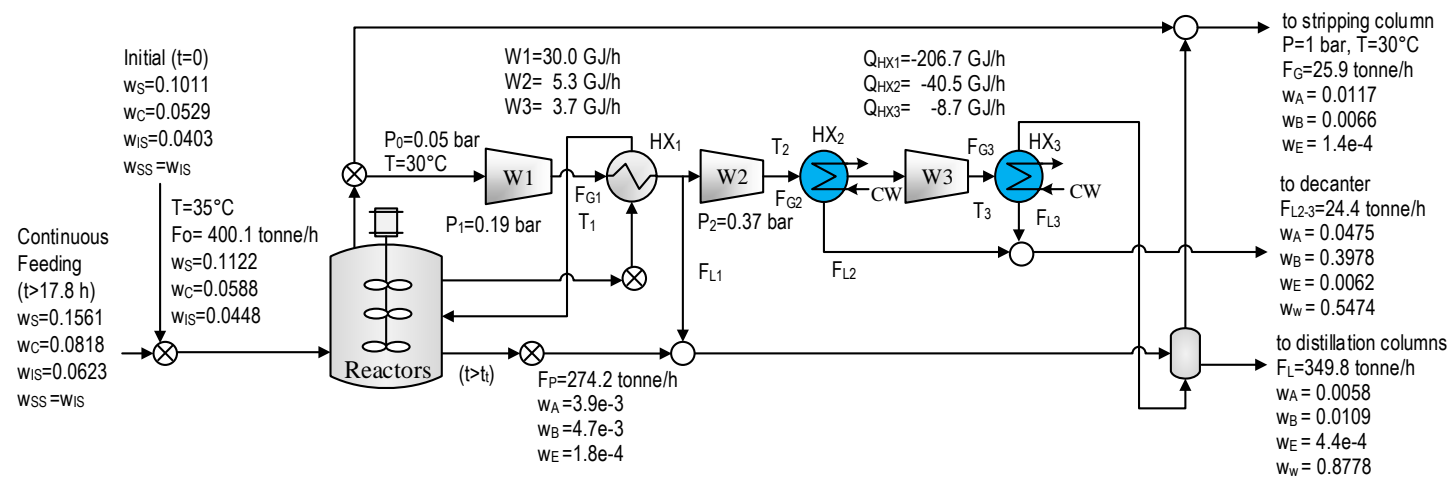

Fig. 1. ISPR-V, fed-batch flowsheet. CW, cold water. $\mathrm{HX}$ is heat exchanger. $\mathrm{F}_{\mathrm{L}}$ is the liquid flow after condensation. $\mathrm{W}$ is compressor work. $\mathrm{w}$ is mass fraction. $\mathrm{T}$ is temperature. $\mathrm{w}_{\mathrm{s}}$ and $\mathrm{Wc}$ are the average compositions of substrate and cellulose in the detoxified corn stover. Wis and Wss are the insoluble solids and soluble solids, respectively. $F$ represents mass flow. $S$ is the total substrate (cellulose plus xylose and glucose) and $C$ is cellulose. The subscripts $L$ and $G$ represent liquid and gas flow, $A$ is acetone, $B$ is butanol, $\mathrm{E}$ is ethanol, $\mathrm{W}$ is water. The values of the energy requirements and compositions are the 
828

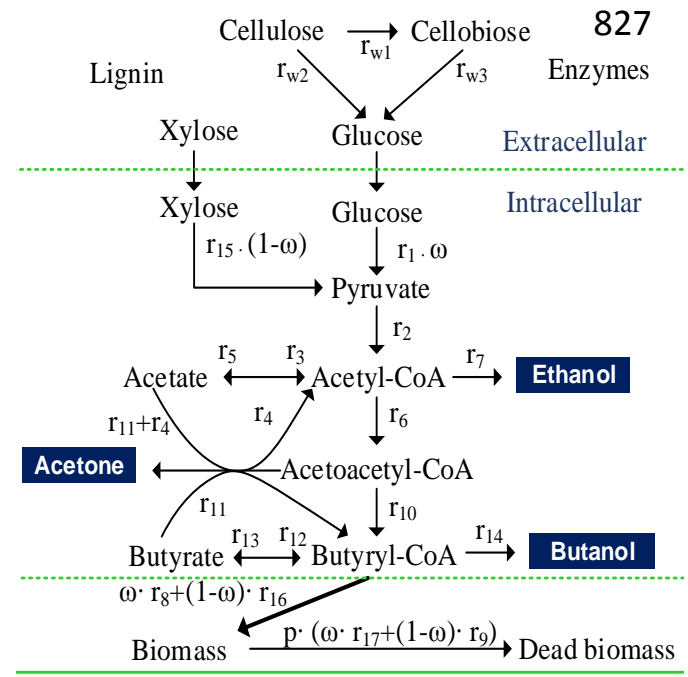

Stoichiometric reactions: $6 \cdot$ Xylose $=5 \cdot$ Glucose

Glucose $\longrightarrow$ Butanol + Water $+2 \mathrm{CO}_{2}$

Glucose+Water $\rightarrow$ Acetone $+4 \mathrm{H}_{2}+3 \mathrm{CO}_{2}$

Glucose $\rightarrow$ 2Ethanol $+2 \mathrm{CO}_{2}$

829 Fig. 2. Biochemical reaction network for simultaneous saccharification and ABE fermentation. In the

830 'extracellular' reactions, the cellulose is converted to glucose and cellobiose. Glucose and xylose are

831 then fermented by Clostridium saccharoperbutylacetonicum N1-4. The gases were assumed to be

832 produced with respect to the stoichiometric reactions for acetone, ethanol and butanol production

833

834

835

836

837

838

839

840

841 

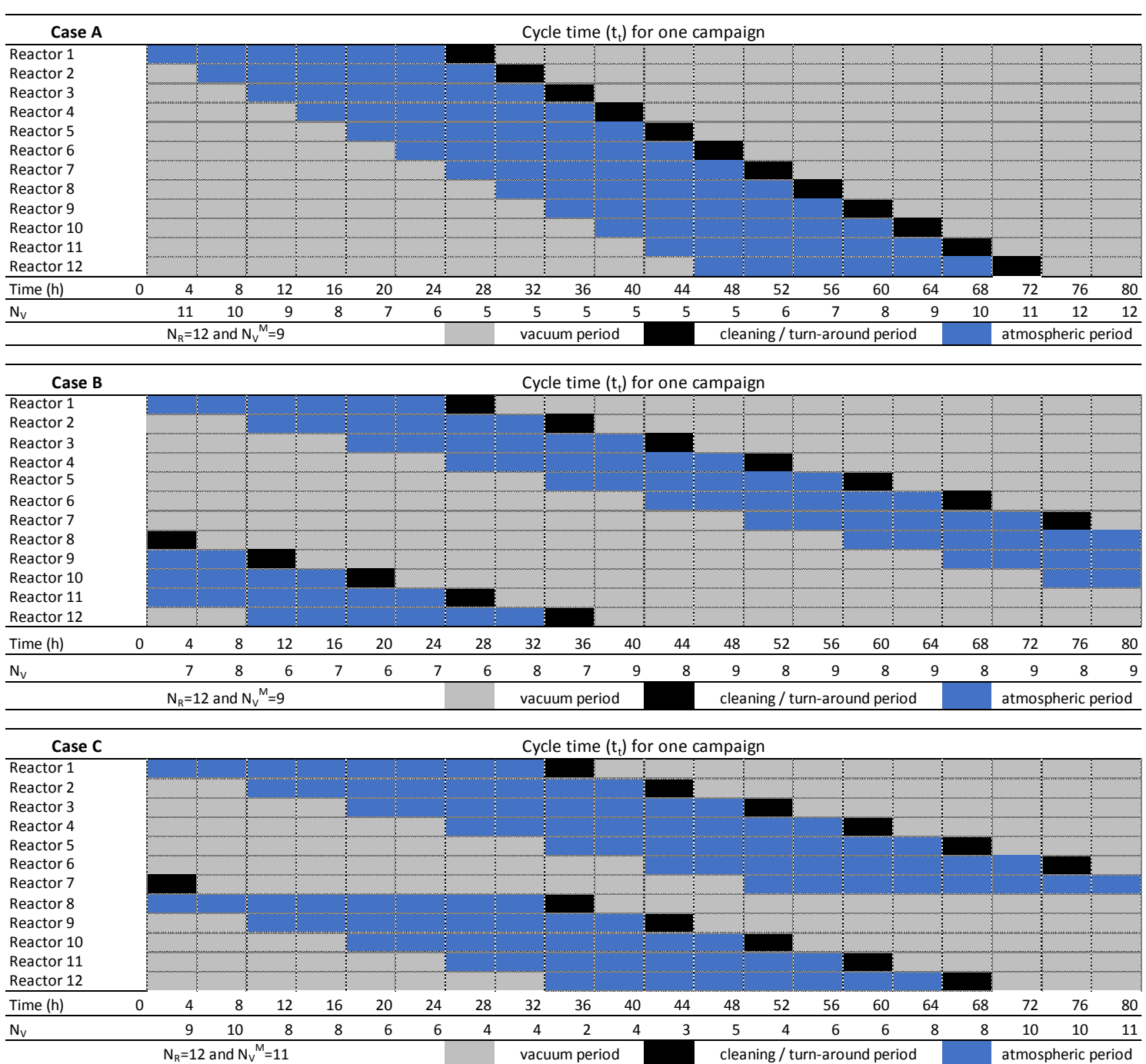

Fig. 3. Example of the graphical method used to calculate the maximum number of reactors operated in the cycle time $\left(N_{V}^{M}\right)$. In this example, the total number of reactors, $N_{\mathrm{R}}$ is 12 and the cleaning/turnaround time is $5 \%(4 \mathrm{~h})$ of the cycle time $\left(t_{t}\right), 80 \mathrm{~h}$. Nv is the number of reactors operated under vacuum in a determined interval of time. Three scenarios are shown: Case A, time between the start-up of reactors $\left(t_{d}\right)$ is equal to $5 \%$ of $t_{t}$ and the vacuum time of one reactor in the cycle time $\left(t_{v}\right)$ was $52 \mathrm{~h}$ ( $65 \%$ of $t_{t}$ ). Case B, $t_{d}$ is equal to $10 \%\left(8 \mathrm{~h}\right.$ ) of $t_{t}$ and $t_{v}$ was $65 \%$ of $t_{t}$. Case $\mathrm{C}, t_{v}$ is $44 \mathrm{~h}\left(55 \%\right.$ of $\left.t_{t}\right)$ and 


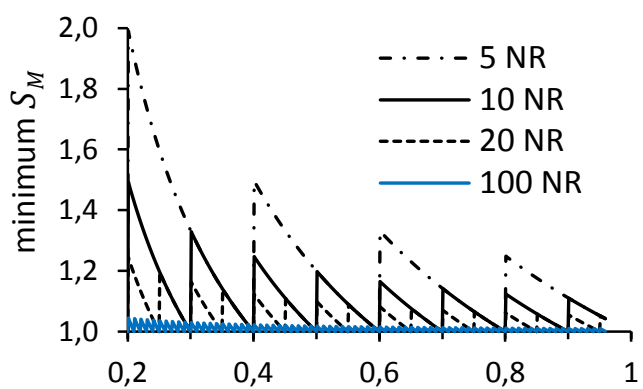

(a) Vacuum operation $\left(t_{v} / t_{t}\right)$

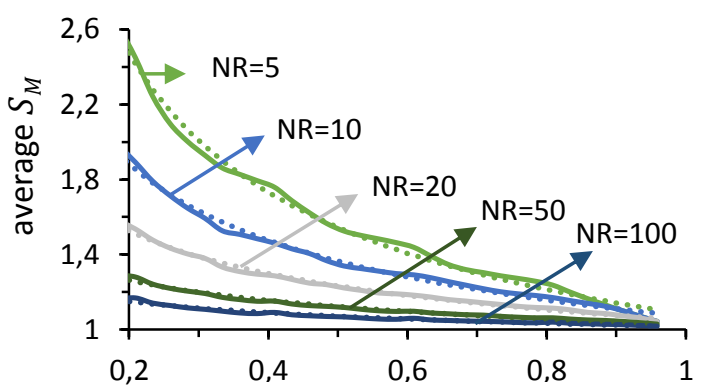

(b) Vacuum operation $\left(t_{v} / t_{t}\right)$
856

857

858

859

860

861

862

863

864

865

866

867

868

869

870

871

872

873

874

875

876

877

67

Fig. 4. Effect of the number of reactors (NR) on the ratio $S_{M}$. Turn-around time of the reactor $\left(\mathrm{t}_{1}\right)$ is 4 hours, $t_{v}$ is the time of vacuum operation of reactor $\left(0<t_{v}<96 \mathrm{~h}\right)$ and $t_{t}$ the cycle time (100 h). In case (a), the minimum $S_{M}$ was found using the optimal time between start-up of the reactors $\left(t_{d}\right)$. Whilst in case (b), $S_{M}$ was the mean value a $t_{d}$ between 0 and $100 \%$ of $t_{t}$. In case (b), continuous lines represent the rigorous calculation and dashed line is from a short-cut method

4

5

66

868

869




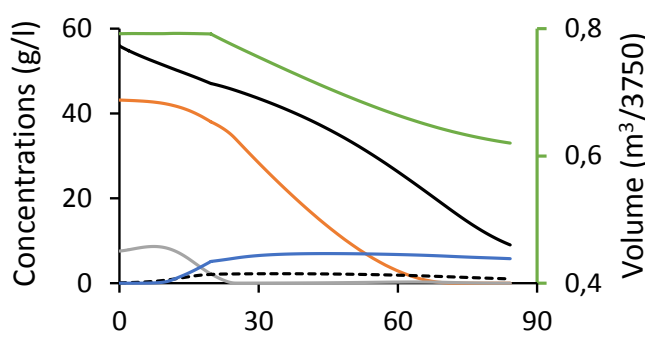

(a) Time (h)

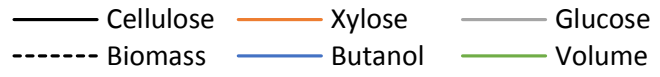

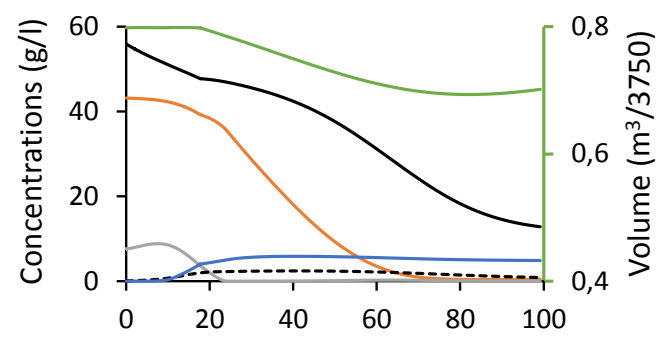

(b) Time (h) Xylose Butanol Glucose Volume

Fig. 5. Batch and fed-batch profiles for butanol production from corn stover via vacuum 


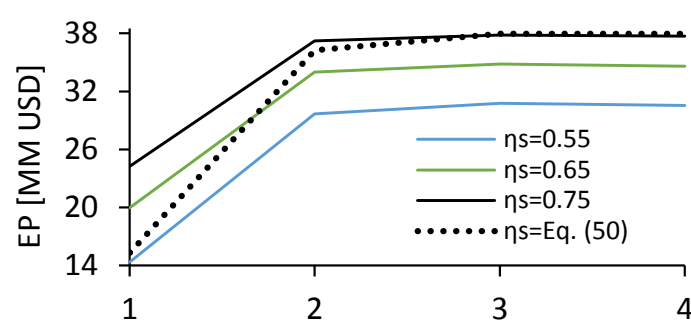

(a) Number of stages of compression

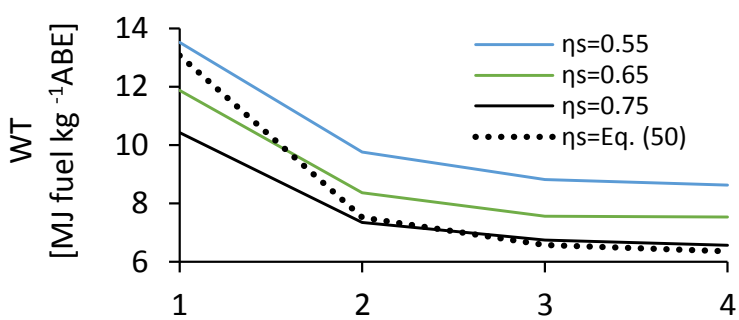

(b) Number of stages of compression

898 Fig. 6. Effect of the number stages of compression on the economic potential $(E P)$ and the

899 total compressor work (WT). Fed-batch operating mode with optimal EP estimates for 